\title{
Ergotamine abuse and extra-hepatic portal hypertension.
}

\author{
P.E. Fisher*, D.B.A. Silk, N. Menzies-Gow and M. Dingle \\ Department of Gastroenterology and Nutrition, Central Middlesex Hospital, Acton Lane, London NW10 7NS, \\ $U K$.
}

\begin{abstract}
Summary: Arterial complications following ergotamine therapy have been well recognized since the beginning of this century. Venous complications, however, have only rarely been reported. A 48 year old Nigerian woman developed extra-hepatic portal hypertension coincident with a chronic overdosage of ergotamine. The literature elucidating the possible mechanisms involved is reviewed.
\end{abstract}

\section{Introduction}

It has long been recognized that toxicity due to ergotamine overdosage is directly related to its arteriospastic action (Yater \& Cahill, 1936; Gould et al., 1936). This most commonly results in ischaemia of the extremities (Cranley et al., 1963; Sutton \& Preston, 1970). Also documented are spasm of the coronary (Yater \& Cahill, 1936), carotid (Greene et al., 1977), cranial and renal arteries (Fedotin \& Hartman, 1970; Greene et al., 1977). Arteriographic studies have demonstrated spasm of the coeliac axis and superior mesenteric artery (Greene et al., 1977; Stillman et al., 1977) and even aorto-iliac spasm has been recorded (Glazer et al., 1966; Fedotin \& Hartman, 1970).

Only very rarely has a specific venous complication, as a direct result of ergotamine poisoning, been reported. Included in the literature are cases of thrombophlebitis (Greene, 1959) and deep venous thrombosis of the leg (Mintz et al., 1974), following ergotamine administration.

The dearth of reported cases of venous complications following ergotamine abuse may, in part, be due to the more nebulous clinical presentation of venous occlusion, as opposed to the clear-cut clinical features of arterial insufficiency.

This report describes an association between the development of extra-hepatic portal hypertension and the chronic overdosage of ergotamine, an as yet unrecognized complication of ergotamine therapy.

*Correspondence and present address: P.E. Fisher, B.Sc., M.B., B.S., Department of Pathology, Kings College Hospital, London SE5 9RS.

Accepted: 4 July 1984

\section{Case report}

A 48 year old Nigerian woman presented with an acute left-sided hemiparesis. She had suffered with severe classical migraine for $8 \mathrm{y}$, and her medication included oral ergotamine tartrate with caffeine (Cafergot, Wander Pharmaceuticals) for the acute migraine episode. She had however been taking $6 \mathrm{mg} /$ day for at least the 3 months immediately previous to her admission. This constitutes a substantial chronic overdosage of ergotamine, which has a recommended maximum dose of $12 \mathrm{mg}$ in any one week, and a recommended break of at least 4 days between courses for an acute migraine attack.

Her past medical history included a Caesarian section 25 y previously, and a laparotomy for secondary infertility $10 \mathrm{y}$ previous to this presentation, both of which were uncomplicated. No abnormalities of the portal system were noted at either of these operations. She had otherwise, apart from her migraine, been perfectly well. Examination at presentation revealed a left-sided hemiparesis. She was normotensive and had no signs of cardiovascular disease. All investigations, including computerized tomography of the head, were normal.

It was thought unlikely that her hemiparesis represented a thromboembolic episode, and the diagnosis was made of cranial artery spasm resulting in an ischaemic episode, either due directly to a severe attack of migraine, or, more likely, due to systemic ergotamine toxicity, a well recognized complication of ergotamine abuse (Brazeau, 1970). Ergotamine was therefore withdrawn from her treatment regimen, and the hemiparesis completely resolved within one week.

One month later she re-presented with melaena and 
frank rectal bleeding, requiring resuscitation with 5 units of blood. She had been currently ingesting large quantities of aspirin to cope with a particularly severe migraine attack. Physical examination at this time revealed splenomegaly, a finding not noted previously. Otherwise examination was entirely normal.

Endoscopy revealed severe gastric erosions as expected, but an unexpected coincidental finding was the disclosure of grade 4 oesophageal varices. All blood tests, including liver function tests, were normal. Liver biopsy revealed a normal histology.

Splenoportograms and superior mesenteric angiograms did not reveal any recognizable splenic, superior mesenteric or portal veins. At laparotomy the angiographic findings were confirmed, with completely fibrosed splenic, superior mesenteric and portal veins. Splenomegaly was noted to three times normal size and there was a profusion of dilated, tortuous, variceal veins extending beyond the oesophago-gastric junction. No shunt procedure was possible, and injection sclerotherapy of her oesophageal varices was performed. She remains well at current follow-up.

\section{Discussion}

In up to $50 \%$ of patients presenting with extra-hepatic portal hypertension no cause is found (Webb \& Sherlock, 1979). The present patient is of interest, because she had a well documented history of ergotamine abuse. This was thought to have been responsible for her episode of cerebral ischaemia, and the possibility exists that the ergotamine abuse could in addition have played an aetiological role in her extra-hepatic portal hypertension.

The pathogenesis of arterial disease induced by ergotamine and the clinical sequelae have been well documented. Ergotamine causes vasospasm, the production of mural thrombi and, microscopically, there is vascular smooth muscle hypertrophy and reduction of vessel lumen diameter (Yater \& Cahill, 1936; Cranley et al., 1963). These effects, on both arteries and veins, are mediated by partial $\alpha$-adrenoceptor agonism (Boissier, 1978; Muller-Schweinitzer \& Sturmer, 1974; Aellig, 1975), enhanced prostaglandin E production (Muller-Schweinitzer, 1974; MullerSchweinitzer \& Brundell, 1975) and a direct action on the vascular smooth muscle even more potent than noradrenaline (Mikkelsen et al., 1981).

Although, in general, veins are poor responders to vasospastic stimulation, portal and superior mesenteric veins have been shown to be exceptional, contracting vigorously in response to a variety of catecholamines (Richardson \& Withrington, 1978, 1979).
Animal studies involving perfusion of the portal vein $\frac{\text { of }}{2}$ with ergotamine (Richardson \& Withrington, 1977), ‡ have shown classical dose-response contractions, with 3 consequently markedly reduced portal blood flow. $\stackrel{\mathbb{\complement}}{\complement}$ Chronic repeated dosage with ergotamine resulted in $c$ an increased number of $\alpha$-adrenoceptors with corre- $\vec{F}$ sponding increased sensitivity to ergotamine. In vivo human studies on forearm and hand veins (Aellig, 응 1976; Brooke \& Robinson, 1970), although of lesser $\frac{\bar{c}}{\overline{0}}$ magnitude, bear out the validity of these in vitro $\frac{\vec{\sigma}}{\sigma}$ studies, a dose-dependent venoconstriction resulting $\propto$ from the administration of ergotamine (Aellig, 1981;œ Tfelt-Hansen et al., 1982a).

Ergotamine has a prolonged venospastic action (Aellig, 1981; Tfelt-Hansen et al., 1982b), lasting for at $\vec{\omega}$ least $8 \mathrm{~h}$ after a single oral dose. There is also $\frac{\partial}{\partial}$ significant accumulation (Ala-Hurula et al., 1979), blood levels rising for several days after dosage interruption. Ergotamine has thus been shown to produce a reliable, long-lasting increase in venous tone $\overrightarrow{-}$ and has been proposed for clinical use in the treatment $T$ of orthostatic hypotension (Mellander \& Nordenfelt, $\stackrel{\text {, }}{\vec{s}}$ 1976).

It is clear that this patient ingested a substantial overdose of a caffeine-enhanced preparation of $\bar{z}$ ergotamine regularly, over a sustained period. The consequent accumulation would have resulted in a $\vec{\ominus}$ hugely elevated portal blood level within a few week, although extensive hepatic first-pass metabolis (Nimmerfall \& Rosenthaler, 1976) would have prote⿳亠二口犬: ted her from undue systemic toxicity.

There are thus experimental grounds for believing that by virtue of its potent $\alpha$-agonist action, enhanced $\stackrel{0}{\circ}$ prostaglandin-E synthesis and direct vascular smooth $\stackrel{\varnothing}{\varrho}$ muscle stimulation, ergotamine may have produced a $\overrightarrow{\overrightarrow{0}}$ sustained constriction of the portal veins in this 3 patient. It seems possible that the development of an increased number of adrenoceptors together with a rising portal blood level of ergotamine would not only흘 have exacerbated this sustained spasm, but finally would have led to hypertrophy of the vascular smooth $\frac{5}{3}$ muscle, intimal damage and mural thrombus forma- $\frac{3}{6}$. tion. The resultant extra-hepatic portal hypertension $\delta$ can create extensive porto-systemic anastamoses and portal vein fibrosis within a few months (Gibson et al., 윽 1965). This would have allowed ergotamine to reach $\frac{D}{D}$ toxic systemic levels, bypassing hepatic metabolism via these anastamoses, possibly accounting for this $\mathrm{N}$ patient's initial presentation with an episode of cerebral arterial spasm.

In conclusion, we present evidence suggesting that $\underset{\omega}{\mathbb{N}}$ the onset of portal hypertension in this patient was related to ergotamine abuse, a hitherto undescribed $Q$ cause of extra-hepatic portal hypertension. 
AELLIG, W.H. (1975). Studies on the venoconstrictor effect of ergot compounds in man. Triangle, 14, 39.

AELLIG, W.H. (1976). Influence of ergot compounds on compliance of superficial hand veins in man. Postgraduate Medical Journal, 52, 21.

AELLIG, W.H. (1981). A new technique for recording compliance of human hand veins. British Journal of Clinical Pharmacology, 11, 237.

ALA-HURULA, V., MYLLYLA, V.V., ARVELA, P., KARKI, N.T. \& HOKKANEN, E. (1979). Systemic availability of ergotamine tartrate after three successive doses and during continuous medication. European Journal of Clinical Pharmacology, 16, 355.

BOISSIER, J.R. (1978). General pharmacology of ergot alkaloids. Pharmacology, 16, 12.

BRAZEAU, P. (1970). In The Pharmacological Basis of Therapeutics, Goodman, L.S., Gilman, A. (Eds), p. 902. Macmillan Inc: New York.

BROOKE, O.G. \& ROBINSON, B.F. (1970). Effect of ergotamine and ergometrine on forearm venous compliance in man. British Medical Journal, 1, 139.

CRANLEY, J.J., RAYMOND, J.K., STRASSER, E.S. \& CHARLES, D.H. (1963). Impending gangrene of four extremities secondary to ergotism. New England Journal of Medicine, 269, 727.

FEDOTIN, M.S. \& HARTMAN, C. (1970). Ergotamine poisoning producing renal arterial spasm. New England Journal of Medicine, 283, 518.

GIBSON, J.B., JOHNSTON, G.W., FULTON, T.T. \& RODGERS, H.W. (1965). Extrahepatic portal-venous obstruction. The British Journal of Surgery, 52, 129.

GLAZER, G., MYERS, K.A. \& DAVIES, E.R. (1966). Ergot poisoning. Postgraduate Medical Journal, 42, 562.

GOULD, S.E., PRICE, A.E., GINSBERG, H.I. (1936). Gangrene and death following ergotamine tartrate (Gynergen) therapy. Journal of the American Medical Association, 106, 1631.

GREENE, R. (1959). Migraine. British Medical Journal, 1, 574.

GREENE, F.L., ARIYAN, S. \& STANSEL, JR., H.C. (1977). Mesenteric and peripheral vascular ischaemia secondary to ergotism. Surgery, 81, 176.

MELLANDER, S. \& NORDENFELT, I. (1976). Peripheral and central circulatory effects of dihydroergotamine. Postgraduate Medical Journal, 52, (suppl. 1). 17.

MIKKELSEN, E., LEDERBALLE-PEDERSEN, O., ØSTERGAARD, J.R. \& ELLEBAEK-PEDERSEN, S. (1981). Effects of ergotamine on isolated human vessels. Archives Internationales Pharmacodynamie et de Therapie, 252, 241.
MINTZ, U., BAR-MEIR, S. \& DEVRIES, A. (1974). Ergotamineinduced venous thrombosis. Postgraduate Medical Journal, 50, 244.

MULLER-SCHWEINITZER, E. (1974). Studies on the peripheral mode of action of dihydroergotamine in human and canine veins. European Journal of Pharmacology, 27, 231.

MULLER-SCHWEINITZER, E. \& STURMER, E. (1974). Investigations on the mode of action of ergotamine in the isolated femoral vein of the dog. British Journal of Pharmacology, 51, 441.

MULLER-SCHWEINITZER, E. \& BRUNDELL, J. (1975). Enhanced prostaglandin synthesis contributes to the venoconstrictor activity of ergotamine. Blood Vessels, 12, 193.

NIMMERFALL, F. \& ROSENTHALER, J. (1976). Ergot alkaloids: hepatic distribution and estimation of absorption by measurement of total radioactivity in bile and urine. Journal of Pharmacokinetics and Biopharmaceutics, 4, 57.

RICHARDSON, P.D.I. \& WITHRINGTON, P.G. (1977). The effects of intraportal injections of noradrenaline, adrenaline, vasopressin and angiotensin on the hepatic portal vascular bed of the dog. British Journal of Pharmacology, 59, 293.

RICHARDSON, P.D.I. \& WITHRINGTON, P.G. (1978). Alpha and beta adrenoceptors in the hepatic portal venous vascular bed of the dog. British Journal of Pharmacology, 62, 376P.

RICHARDSON, P.D.I. \& WITHRINGTON, P.G. (1979). Responses of the hepatic arterial and portal venous vascular beds of the dog to intra-arterial infusions of noradrenaline and adrenaline. British Journal of Pharmacology, 66, 82P.

STILLMAN, A.E., WEINBERG, M., MAST, W.C. \& PALPANT, S. (1977). Ischaemic bowel disease attributable to ergot. Gastroenterology, 72, 1336.

SUTTON, D. \& PRESTON, B.J. (1970). Angiography in peripheral ischaemia due to ergotism. British Journal of Radiology, 43, 776.

TFELT-HANSEN, P., PAALZOW, L. \& IBRAHEEM, J.J. (1982a). Bioavailability of sublingual ergotamine. British Journal of Clinical Pharmacology, 13, 239.

TFELT-HANSEN, P., EICKHOFF, J.H. \& OLESEN, J. (1982b). Duration of the biological effect of ergotamine tartrate. Advances in Neurology, 33, 315.

WEBB, L.J. \& SHERLOCK, S. (1979). The aetiology, presentation and natural history of extra-hepatic portal venous obstruction. Quarterly Journal of Medicine, 192, 627.

YATER, W.M. \& CAHILL, J.A. (1936). Bilateral gangrene of feet due to ergotamine tartrate used for pruritus of jaundice. Journal of the American Medical Association, 106, 1625. 